\title{
EDUCAÇÃO E TRABALHO: COMO DESENVOLVER UMA RELAÇĀO VIRTUOSA?
}

\author{
Marcio PochmanN ${ }^{*}$
}

RESUMO: Este artigo discute as relações entre educação e trabalho. A tese principal é que a reestruturação da educação necessita articular o estágio de desenvolvimento econômico e a expectativa média de vida da população.

Palavras-chave: Educação. Trabalho. Desemprego. Juventude.

\section{EDUCATION AND WORK: \\ HOW COULD WE DEVELOP A VIRTUOUS RELATION?}

ABSTRACT: This paper discusses the relations between education and work, in Brazil. Its main thesis is that the restructuring of education has to be articulated with an economic development stage and the mean expectation of life of the population.

Key words: Education. Work. Unemployment. Youth.

* Professor licenciado do Instituto de Economia e pesquisador do Centro de Estudos Sindicais e de Economia do Trabalho da Universidade Estadual de Campinas (UnICAMP); secretário do Desenvolvimento, Trabalho e Solidariedade do Município de São Paulo. 
Educação e trabalho: como desenvolver uma relação virtuosa?

\section{Apresentação}

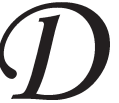

urante a década de 1990, o Brasil apresentou uma melhora não desprezível nos seus índices educacionais quantitativos. Reduziu a taxa de analfabetismo e aumentou o nível médio de escolaridade, ainda que a um ritmo menor do que nas décadas anteriores. ${ }^{1}$

Da mesma forma, a expectativa média de vida da população continuou elevando-se. Diante das mudanças tecnológicas, com várias inovações no campo da saúde, entre outros, aumenta-se, mais rapidamente do que em outros períodos, o tempo médio de vida da população, alterando significativamente a situação da juventude.

Paralelamente a tudo isso, acentuaram-se os níveis de desemprego, assim como a precariedade, o sobretrabalho ${ }^{2}$ e a deterioração dos níveis de renda, especialmente entre as faixas etárias mais jovens. Com a continuidade ao longo dos anos de 1990 da manifestação da crise do desenvolvimento econômico brasileiro - a mais longa desde 1840 -, a degradação do mercado de trabalho persistiu mais acentuadamente.

Em função desse cenário, como se apresentou a relação entre educação e trabalho? O objetivo deste artigo é o de desenvolver o argumento de que a deterioração das condições de funcionamento do mercado de trabalho, ao invés de ser contida pela melhoria educacional, contribuiu para o desperdício e o desgaste de habilidades educacionais em atividades precárias e de baixa qualidade.

Em contrapartida, a persistência do desempenho tão desfavorável do mercado de trabalho induziu ainda mais as segmentações ocupacionais, excluindo os mais pobres dos empregos nos segmentos educacionais mais elevados. De certa forma, ampliou-se consideravelmente o processo discriminatório no interior do mercado de trabalho, sobretudo entre distintas faixas etárias (jovens e adultos), raças e gênero.

Tal círculo vicioso impediu que a educação revelasse o seu potencial transformador das relações humanas e da agregação de valor à produção no Brasil. No contexto de emergência da sociedade do conhecimento, os requisitos educacionais do emprego ampliaram-se.

Entretanto, a incapacidade de superação da crise do desenvolvimento econômico nacional, associada ao ciclo de financeirização da riqueza e à estagnação dos investimentos, especialmente nos setores mais intensivos em tecnologia, estimulou mais ainda a disparidade 
extrema entre os distintos níveis de renda. Assim, o Brasil terminou afastando-se das oportunidades de assimilação das tendências potencialmente positivas da sociedade do conhecimento, posto que se caracteriza cada vez mais como uma sociedade de baixos salários voltada à exportação de bens primários (agronegócios) e de consumo ostentatório de serviços pessoais de poucas famílias ricas.

Sair deste círculo vicioso é vital para que o país possa participar de forma mais dinâmica do novo cenário internacional e ampliar o dinamismo interno, o que favorece que a educação passe a significar novamente oportunidades redobradas de ascensão social e, não como hoje, uma defesa, aliás profundamente precária contra a elevação do desemprego e a queda do nível de renda.

Não parece ser por outro motivo que o país vive um quadro de guerra civil não declarada, com homicídios praticados anualmente no Brasil representando 9,4\% de todos os assassinatos no mundo. Também com a massa humana sem trabalho, que representa quase $5 \%$ do desemprego mundial, apesar de o país significar somente $2,8 \%$ de toda a população do globo terrestre, ganhou nova dimensão a emigração de brasileiros, especialmente aqueles de maior escolaridade, para outras nações com melhores horizontes de mobilidade social. ${ }^{3}$

Em síntese, o presente artigo procura evidenciar os principais desafios colocados à população brasileira, fundamentalmente ao jovem num mundo do trabalho tortuoso como o verificado desde o último quartel do século passado. Da mesma forma trata-se também de buscar relacionar particularmente as variáveis como educação e trabalho, em busca de novas políticas de inclusão social já em curso no país.

\section{O jovem na crise do mercado de trabalho}

Em pleno limiar do século XXI, a participação relativa do segmento etário de 15 a 24 anos no total da população economicamente ativa é de $25 \%$, embora o jovem responda por $50 \%$ do desemprego nacional. ${ }^{4}$ Ao passo que a taxa de desemprego aberto dos jovens gira em torno dos $18 \%$, a taxa média nacional esteve em $9,4 \%$ do total da força de trabalho, segundo o IBGE (PNAD) no ano de 2001.

Além disso, nota-se também que, do total de 33,5 milhões de jovens, apenas 38\% (12,6 milhões) eram inativos, ao passo que 51\% 
Educação e trabalho: como desenvolver uma relação virtuosa?

(16,8 milhões) possuíam algum vínculo empregatício e 11\% (3,7 milhôes) estavam desempregados. Somente a metade do total da população juvenil estudava, sendo a maior parte fora da série escolar correspondente à faixa etária.

A maior parte dos que não estudavam era composta de jovens que trabalhavam. Isto é, 10,6 milhões de jovens trabalhavam, porém não estudavam. Da mesma forma, percebe-se que entre os jovens inativos havia $35,3 \%$ que não estudavam, equivalendo a 4,5 milhões de brasileiros (13,6\% de todos os jovens no país) que não trabalhavam, não estudavam nem procuravam emprego. ${ }^{5}$

Tal conjuntura refere-se possivelmente a uma situação de inatividade forçada, que se associa à emergência da nova exclusão no Brasil. ${ }^{6}$ Isso se expressa, em grande medida, com relação à escolaridade, posto que, do total dos jovens que estudam, 43,2\% estavam no ensino fundamental, $43,5 \%$ estavam cursando o ensino médio e apenas $13,3 \%$ estavam no ensino superior.

Em contrapartida, quando se levam em consideração os níveis de renda diferenciados, podem ser identificadas enormes desigualdades nas oportunidades de educação e trabalho entre os jovens. Constata-se que, na ocupação, são os jovens pertencentes às famílias de maior renda aqueles com maior acesso aos trabalhos assalariados $(77,1 \%)$, sendo que $49,0 \%$ dos jovens ricos que trabalham possuem contrato formal.

Para os jovens pertencentes às famílias de baixa renda, somente $41,4 \%$ possuem empregos assalariados, sendo ainda bem menor o contingente de ocupados assalariados com contrato formal (25,7\%). Sem acesso ao assalariamento e, sobretudo, ao contrato formal, há inequivocamente maior exclusão dos benefícios da legislação social e trabalhista para os jovens de baixa renda no Brasil.

No caso das categorias ocupacionais, observa-se também uma forte desigualdade entre jovens ricos e pobres. A presença de jovens de maior renda no trabalho doméstico é residual $(7,9 \%)$, sendo que apenas $7 \%$ percebem algum rendimento desse trabalho. No caso dos jovens de baixa renda, a participação no trabalho doméstico é de quase a metade $(46,2 \%)$, com mais de $26,8 \%$ remunerados.

Ainda com relação ao funcionamento do mercado de trabalho, verifica-se que o desemprego de jovens de baixa renda é bem maior $(26,2 \%)$ que o desemprego dos jovens de renda elevada (11,6\%). Por 
fim, cabe ainda destacar a relação entre o nível de renda e a educação, uma vez que, entre os jovens pobres, apenas $38,1 \%$ estudavam, ao passo que, entre os jovens ricos inativos, $80 \%$ estudavam.

Para parcela significativa de jovens filhos de pais pertencentes às classes de renda média e alta tem havido uma pressão considerável para o abandono do país em busca de melhores perspectivas ocupacionais e de renda, ao passo que aos jovens filhos de pais pobres a violência tem emergido em meio à falta de um horizonte de ocupação e renda decente.

\section{Dinâmica educacional e do mercado de trabalho}

O que acontece com o segmento jovem da sociedade brasileira é apenas a face mais visível do drama social de um país estagnado economicamente nos últimos 24 anos. Isso porque a dinâmica excludente do mercado de trabalho brasileiro vem deteriorando as vantagens potencialmente oferecidas pela educação, além de aumentar as desigualdades de renda para os mesmos níveis educacionais.

Quanto à questão da escolaridade, percebe-se que as taxas de desemprego se elevaram a um ritmo mais rápido justamente para os níveis de maior escolaridade entre 1992 e 2002. Para os segmentos com 14 anos de estudo, a desocupação cresceu 76,9\%, 3 vezes a mais que o ritmo de crescimento do desemprego para os segmentos educacionais com até 3 anos de estudo.

Contrariando a teoria do capital humano, a elevação dos níveis de escolaridade - num quadro de estagnação econômica, baixo investimento em tecnologia e precarização do mercado de trabalho - acaba se mostrando insuficiente para potencializar a geração de trabalho. Apesar disso, prosseguem as vertentes daqueles que acreditam no papel independente e autônomo da educação com relação à mobilidade social ascendente. $^{7}$

O mais surpreendente, entretanto, é perceber que, se analisadas as informaçóes para o ano de 2002, as taxas de desemprego nos grupos de maior renda sofrem uma inflexão para baixo entre a faixa de 9 anos de estudo e a de 15 ou mais anos de estudo, ao passo que na classe baixa, à medida que se eleva a escolaridade, cresce o desemprego. Ora, num contexto de mercado de trabalho apertado e pouco dinâmico, os empregos mais nobres e de melhor qualidade acabam 
Educação e trabalho: como desenvolver uma relação virtuosa?

sendo preservados para os mais ricos. Além do preconceito racial, agrava-se o preconceito de classe.

\section{Gráfico 1}

Brasil - Evolução da taxa de desemprego por nível de escolaridade, 1992 e 2002

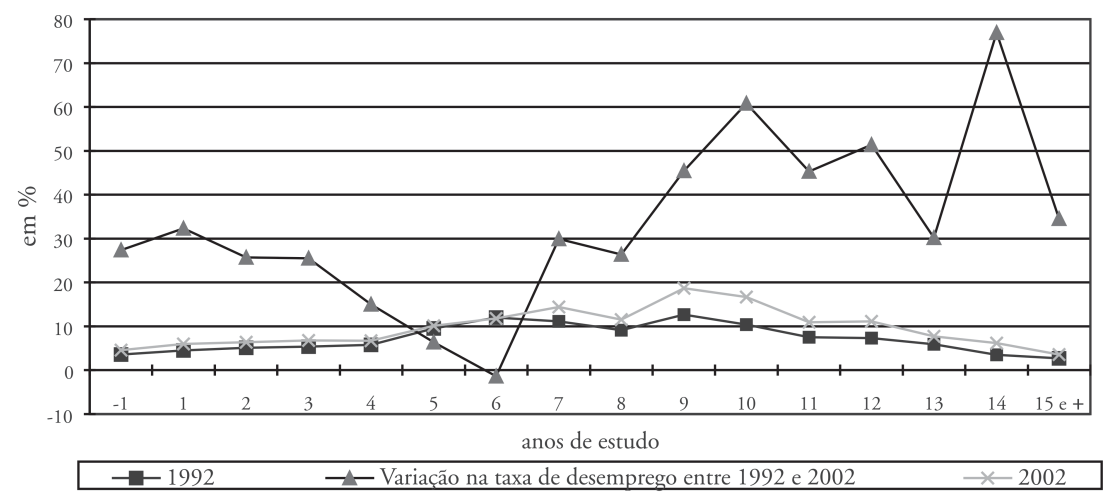

Fonte: IBGE (PNAD) - Elaboração: SDTS/PMSP

Um acompanhamento da dinâmica do emprego por nível educacional e faixa de renda permite dar conta desta realidade. Em primeiro lugar, vale ressaltar a queda da participação no total de ocupados das pessoas com menos de 1 ano de instrução (analfabetas), de 17,9\% para $10,7 \%$ entre 1992 e 2002 . No extremo oposto, a participação daqueles com mais de 15 anos de estudo (curso superior completo) no conjunto dos ocupados salta de $5,1 \%$ para $7,4 \%$ ao longo do período. Enquanto existiam, no início da década de 1990, 3,3 milhões de trabalhadores com curso superior, 10 anos depois eram 5,8 milhões os trabalhadores formados, um acréscimo de $75 \%$.

Parece também importante ressaltar que, à medida que se eleva a escolaridade da população de baixa renda, acompanha, em indicadores mais expressivos, o desemprego. $\mathrm{O}$ mercado de trabalho, diante da enorme escassez de emprego e do elevado excedente de mão-de-obra no país, termina observando a manifestação mais evidente da discriminação, sobretudo quando se trata da população de menor renda e mais escolaridade.

Dessa forma, nota-se que, do ponto de vista da oferta educacional mais escolarizada, o desempenho do Brasil na década passada mostrou incrementos importantes, ainda que se possa questionar acerca da quali- 
dade da educação fornecida, bem como dos seus altos custos para trabalhadores, especialmente para os de baixa renda. Estes são, sobretudo, os mais penalizados pelo desemprego maior nos níveis de escolaridade.

\section{Gráfico 2}

Renda média (em reais de 2002) dos trabalhadores ocupados, com rendimentos por anos de escolaridade, em 1992 e 2002, e variação no período (em \%)

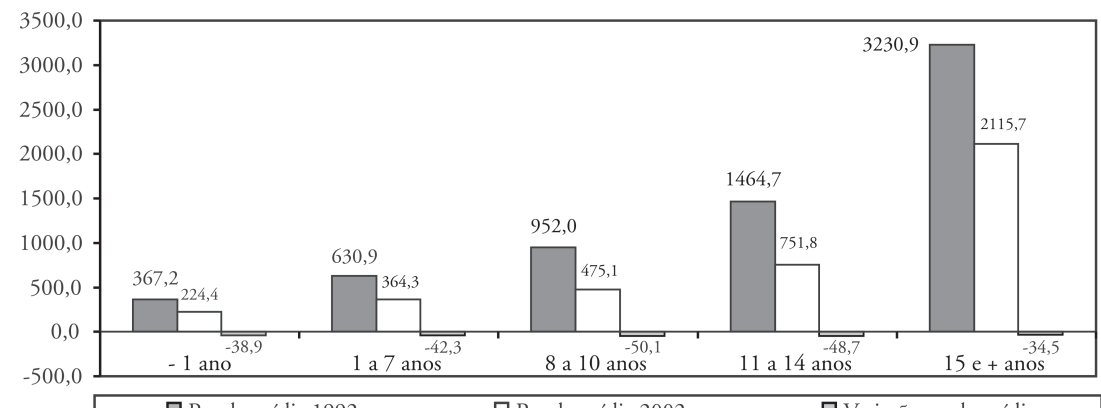

口 Renda média $1992 \quad$ Q Renda média 2002

$\square$ Variaçăo renda média

Fonte: IBGE (PNAD) - Elaboração: SDTS/PMSP. Valores deflacionados pelo ICV/DIEESE.

Em contrapartida, nem mesmo os segmentos educacionais com curso superior foram preservados da queda verificada na renda média. A renda média desse grupo caiu $35 \%$ no período 1992-2002, pouco abaixo do verificado para os analfabetos $(-39 \%)$.

Já os segmentos de 8 a 10 anos e de 11 a 14 anos de estudo foram os mais prejudicados, haja vista que a sua renda caiu pela metade no período analisado. Isso provavelmente ocorreu porque num contexto de demanda contida - já que, em face da estagnação econômica, as empresas restringem o seu nível de produção - a pressão da oferta desses segmentos (com $1^{\circ}$ e $2^{\circ}$ completos) contribui para a queda da renda, o que é agravado pelo cenário de informalidade, precarização e baixa sindicalização da mão-de-obra.

Em síntese, nota-se que, na melhor das hipóteses, a elevação do nível de escolaridade assegurou uma renda maior que nos estratos educacionais inferiores, não garantiu o acesso ao emprego e muito menos uma proteção contra a precarização e deterioração dos níveis de renda em cada estrato. Transformar este círculo vicioso numa relação virtuosa é o grande desafio da sociedade brasileira. 
Educação e trabalho: como desenvolver uma relação virtuosa?

Para tanto, a expansão da escolaridade deve ser vista não apenas do ponto de vista da produtividade, mas especialmente da cidadania. Para que o país possa colher os frutos da sociedade do conhecimento, deve-se aumentar o ritmo de crescimento econômico e de acumulação de capital, promovendo simultaneamente uma redistribuição do tempo de trabalho e da renda. Dessa forma, amplia-se o retorno social do investimento.

\section{Avanço na expectativa média de vida e educação}

Durante o século XX, a expectativa média de vida do brasileiro cresceu significativamente. Em 10 décadas, a esperança de vida ao nascer simplesmente dobrou, passando de 33,4 anos para 63,5 anos para homem e de 34,6 anos para 70,9 anos no caso da mulher.

Para os próximos 30 anos é muito plausível que a esperança média de vida do brasileiro alcance a casa dos 80 anos de idade, aproximando-se do que hoje é realidade na maioria dos países desenvolvidos. No Japão, na França, na Austrália, entre outros países com expectativa média de vida ao nascer superior atualmente aos 80 anos, torna-se possível superar a barreira dos 100 anos nas próximas décadas.

Por decorrência disso, parece ser natural que os conceitos de criança, adolescência, juventude, adulto e velhice tornem-se cada vez mais limitados para dar conta da crescente complexidade do tradicional ciclo de vida. No passado recente, quando a expectativa de vida ao nascer estava um pouco abaixo dos 40 anos, a faixa etária de 15 a 24 anos poderia indicar precisamente um período de tempo compatível com a idéia de transitoriedade que marca a condição juvenil.

Atualmente, quando a expectativa média de vida se encontra ao redor dos 70 anos no Brasil, aproximando-se rapidamente dos 100 anos de idade para as décadas vindouras, torna-se fundamental identificar que está em curso um maior alargamento da faixa etária circunscrita à juventude para algo entre 16 e 34 anos de idade.

Não se trata, evidentemente, de uma mera ampliação da temporalidade que contabiliza a fase juvenil. Trata-se, fundamentalmente, do reconhecimento necessário de que a transição da adolescência para a idade adulta está muito mais complexa do que era no passado, estando a exigir uma agenda pública mais específica voltada para uma faixa etária maior. 


\section{Gráfico 3}

Brasil - Evolução da expectativa de vida ao nascer (em anos)

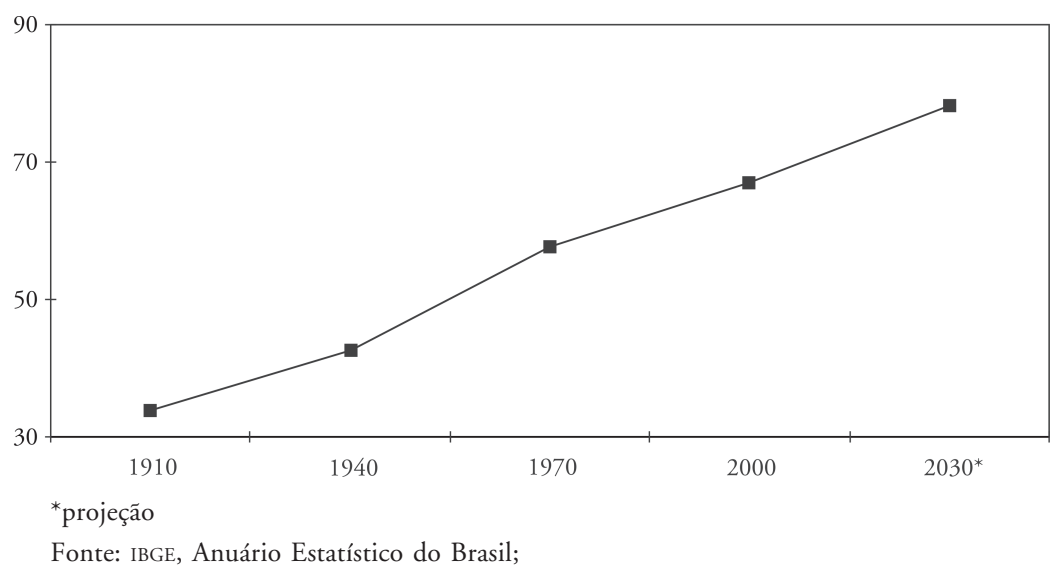

Também quando se considera o curso atual da transição da sociedade industrial para a chamada sociedade do conhecimento, tende-se a observar uma importante mudança na relação entre educação e formação e o mundo do trabalho. Em função disso, o tempo de preparação para o ingresso no mercado de trabalho pode ser bem maior, com a educação e a formação estabelecendo uma relação de continuidade ao longo da vida útil das classes trabalhadoras.

Não sem motivo, torna-se absolutamente fundamental proceder a um conjunto de alteraçôes no atual sistema educacional e de formação profissional. Justamente porque a fase de transição da economia tradicional para uma nova economia exige uma educação geral ampliada e formação continuada ao longo do ciclo de vida ativa das classes trabalhadoras condizente com o estágio de desenvolvimento econômico e o avanço da expectativa média de vida da população. ${ }^{8}$

\section{Experiência exitosa de políticas de inclusão social}

A estratégia em curso no Município de São Paulo de inclusão social é analisada a seguir, justamente por destoar da maior parte das experiências adotadas em termos de políticas públicas no Brasil, uma vez que representa uma das mais amplas açóes de políticas sociais, capaz 
Educação e trabalho: como desenvolver uma relação virtuosa?

de articular e integrar ações educacionais e trabalhistas, envolvendo a cobertura de quase $20 \%$ do conjunto da população. ${ }^{9}$ O conjunto dessa estratégia se encontra dividido em nove programas sociais que se articulam e se integram entre si em torno de três eixos-chave: a redistribuição de renda, a emancipação social, política e econômica e o apoio ao desenvolvimento local..$^{10}$

No primeiro eixo-chave há um verdadeiro choque redistributivo no interior das famílias de pobreza extrema, o que representa uma significativa porta de entrada à estratégia paulistana de inclusão social, tendo na educação e na formação para o trabalho uma ênfase especial. Por intermédio de quatro programas de transferência de renda, buscase atender a distintas condições de pobreza, tendo segmentos etários específicos recebido tratamentos diferenciados.

Ao assegurar temporariamente uma complementação de renda, garante-se o ingresso dos segmentos mais excluídos da população às ações de emancipação social, política e econômica. No caso das famílias de baixa renda, com dependentes de 0 a 15 anos de idade, há o programa Renda Familiar Mínima, ao mesmo tempo em que, para o segmento etário de 16 a 29 anos na condição de baixa renda e desemprego juvenil, há o programa Bolsa Trabalho.

Esses dois programas municipais se encontram associados diretamente à educação, na medida em que asseguram temporariamente a transferência de uma renda vinculada à elevação da escolaridade e ao desenvolvimento de atividades comunitárias, resultando na postergação do reingresso no mercado de trabalho e na melhor preparação para o trabalho como conseqüência. Em síntese, nota-se que, ao se garantir temporariamente uma renda e uma capacitação em atividades comunitárias, busca-se valorizar o protagonismo, o pertencimento e o empoderamento social dos segmentos pauperizados da população. Da mesma forma, há o esforço de parte do Poder Público municipal direcionado ao oferecimento de condiçôes próximas das verificadas somente nas classes de renda média e alta, que podem financiar a formação de seus filhos por mais tempo, permitindo que ingressem no mercado de trabalho suficientemente preparados para ocupar as melhores vagas disponíveis.

O programa Bolsa Trabalho ainda se propõe a atender jovens de baixa renda e com maior escolaridade por meio de cursos pré-vestibulares gratuitos (Bolsa Trabalho Cursinho), integrado ao processo de 
disponibilização de bolsas de estudo em universidades privadas (contrapartida à redução do imposto municipal sobre serviços - ISS) e em universidades públicas. ${ }^{11}$ Outra variável do programa Bolsa Trabalho é a formação no local de trabalho, seja para aqueles jovens na situação de conclusão do ensino médio ou universitário (Bolsa Trabalho Estágio), seja para os recém-formados (Bolsa Trabalho Emprego).

Já para as faixas etárias acima de 20 anos, há também programas específicos de garantia de renda associados à reinserção no mercado de trabalho, compatíveis com alternativas de geração de trabalho e renda. São os casos do programa Operação Trabalho, voltado a desempregados de longa duração e de baixa renda fundamentalmente na faixa etária de 21 a 39 anos de idade, e do programa Começar de Novo, direcionado aos desempregados de baixa renda com 40 anos ou mais de idade. O programa Começar de Novo destaca-se na garantia de formação no local de trabalho para recém-contratados com 40 anos ou mais de idade, bem como financia tanto o pagamento de gastos com transporte na procura por trabalho como a formação no local de trabalho (Começar de Novo Emprego).

Esses dois programas municipais objetivam combinar a complementação temporária de renda com a formação para a geração de trabalho e renda assalariada, autônoma, empreendedora e em atividades comunitárias. Para o contingente de desempregados de longa duração, o programa Operação Trabalho oferece benefício de renda para quem participa de atividades de formação teórica e aprendizagem prática, assim como custeia o vale-transporte associado à qualificação para a procura ativa por trabalho.

Uma vez ingressado nos programas redistributivos, todo beneficiário acessa simultaneamente o segundo eixo programático da estratégia de inclusão social, cujo objetivo é alcançar a emancipação social, política e econômica articulada e integrada com a educação e a formação da cidadania. No caso das famílias do programa Renda Familiar Mínima, busca-se difundir conhecimentos básicos (alfabetização, economia doméstica e orçamentária, saúde e higiene, entre outros), ao passo que para os beneficiários dos demais programas redistributivos existe a possibilidade da escolha de formação específica, após a passagem pelo módulo básico de 2 meses de conhecimento geral (ética, cidadania e cultura política e econômica). 
Educação e trabalho: como desenvolver uma relação virtuosa?

No caso dos módulos específicos, nota-se que eles compreendem o período de 4 a 10 meses, possíveis nas áreas de aprendizagem em empreendedorismo coletivo e individual (programa Oportunidade Solidária), em capacitação profissional para o trabalho assalariado ou autônomo (programa Capacitação Ocupacional e de Aprendizagem em Atividades de Utilidade Coletiva) e em atividades comunitárias (agentes comunitários de lazer, de meio ambiente, de transporte, entre outros). Com relação aos beneficiários necessitados de apoio financeiro para montagem do negócio, compra de equipamentos, vestimenta, entre outros, há uma Central de Crédito Popular São Paulo Confia - o Banco do Povo do Município de São Paulo -, cujo objetivo é a concessão de empréstimos vinculados a custos compatíveis com a capacidade de pagamento do tomador.

Dentro da estratégia de inclusão social também existem portas de saídas comprometidas com as possibilidades de emancipação social, política e econômica da população excluída. É justamente aí que tem importância o eixo-chave de programas direcionados ao apoio do desenvolvimento local, especialmente nas regiōes em que se encontram os beneficiários dos programas redistributivos.

O objetivo desse eixo-chave é a transformação dos locais de moradia e de possível exercício de trabalho, perante a possibilidade de reorganização geográfica das atividades produtivas e de novas formas de reinserção no mercado de trabalho. Simultaneamente também faz parte desse eixo o apoio à reestruturação empresarial, com forte ênfase no desenvolvimento das cadeias produtivas intensivas de mão-deobra e geradoras de negócios, capazes de absorverem maior parcela de beneficiários dos programas sociais e trabalhistas de redistribuição de renda e de educação e cidadania.

Por uma parte, o programa São Paulo Inclui possui uma rede de intermediação de trabalho e de negócios que se originou a partir da passagem dos beneficiários pelos programas redistributivos e emancipatórios. A ligação com o setor produtivo é fundamental, além da operacionalização de uma rede de disponibilização de vagas para que possam ser encaminhados os beneficiários capacitados para uma atividade empreendedora, assalariada, autônoma e comunitária.

Por outra, o programa Desenvolvimento Local preocupa-se em articular e integrar o conjunto de atores relevantes da cidade com os 
beneficiários da estratégia paulistana de inclusão social. Por intermédio dos Fóruns de Desenvolvimento Setorial, busca-se envolver, na forma tripartite, atores empresariais, trabalhadores e universidades para ampliação de setores produtivos como têxtil, móveis, cargas, entre outros.

Assim, a capacitação ocupacional técnica e gerencial de negócios visa a elevar os padrôes de competitividade, incorporando novas tecnologias e estimulando a contratação de beneficiários dos programas sociais. Neste sentido, cabe aos Fóruns de Desenvolvimento Local a função de envolvimento da sociedade civil organizada nas mais distintas regiōes geográficas da cidade, valorizando o empoderamento dos segmentos excluídos em torno da constituição de uma agenda popular de desenvolvimento local. Cabe ainda ao Poder Público municipal procurar incorporar na agenda governamental a gestão das propostas definidas especialmente pelos fóruns locais.

Diante de uma ampla cobertura social, bem como de toda sua complexidade referente à estratégia de inclusão social, que entre 2001 e 2004 atingiu quase $20 \%$ da população paulistana, houve sempre uma forte ênfase na gestão de informação, monitoramento e avaliação. Tudo se iniciou com a construção da Secretaria do Desenvolvimento, Trabalho e Solidariedade (SDTS) voltada para projetos e articulação institucional, com açôes orientadas pela metodologia de intervenção na realidade contida no atlas da exclusão social para os 96 distritos administrativos do Município de São Paulo.

Da mesma forma, a adoção de um cadastramento multiuso permitiu o avanço de dispor de um amplo banco de dados, suficiente para integrar os programas de garantia de renda do Município de São Paulo, do Estado de São Paulo (Renda Cidadã) e do governo federal (antigos programas Bolsa Escola, Bolsa Alimentação, Cartão Alimentaçăo, Agente Jovem, entre outros). Com isso foi possível integrar o conjunto de açōes municipais de atendimento de saúde (dependência química), educação (baixa escolaridade), transporte (serviços a clientes), assistência (população de risco, morador de rua), habitação (moradia), entre outras.

Ademais de possibilitar a sensível redução nos custos administrativos dos programas sociais para menos de $8 \%$ do total dos recursos aplicados (no Brasil, em média o custo meio representa entre 1/3 e 50\%), houve a centralização das ações de inclusão social no espaço territorial. Também se pode ressaltar que o padrão de gestão pública 
Educação e trabalho: como desenvolver uma relação virtuosa?

perseguido pela estratégia de inclusão social para as famílias de baixa renda, que associa garantia temporária de renda com a elevação da escolaridade e ao exercício da aprendizagem teórica e prática em atividades comunitárias e solidárias, valoriza a cidadania, o protagonismo e o pertencimento.

Nesses termos, foi possível constatar, por exemplo, a diminuição na taxa de homicídio do Município de São Paulo, sobretudo no conjunto dos distritos administrativos atendidos por maior tempo pelos programas sociais e trabalhistas. ${ }^{12}$ Ao mesmo tempo, verificou-se uma queda tanto na evasão escolar e como na reprovação, com simultânea elevação na taxa de aprovação escolar. Isso foi mais intenso em regiōes atendidas pelos programas sociais. ${ }^{13}$

Em síntese, observou-se maior percepção a respeito do exercício da cidadania de parte da população beneficiada, considerando-se o comprometimento da estratégia de inclusão social com a emancipação social, política e econômica da população-alvo. ${ }^{14} \mathrm{O}$ avanço na construção de mais uma etapa fundamental no compartilhamento de direitos tem sido alcançado na medida em que segmentos mais pauperizados da população abandonam a condição de massa de manobra política do velho clientelismo e da assistência filantrópica para assumir a posição de protagonismo cidadão.

\section{Considerações finais}

Em conformidade com as páginas anteriores, foi possível notar como o complexo e desfavorável quadro econômico e social brasileiro afeta parcelas significativas da população trabalhadora. A despeito da evolução positiva dos indicadores educacionais, registra-se uma piora no comportamento do mercado de trabalho, com elevação do desemprego e queda do rendimento dos ocupados, inclusive dos trabalhadores com maior grau de instrução.

Os jovens, em especial, são atingidos decisivamente. De um lado pelo desemprego, já que a cada duas pessoas sem trabalho no Brasil, uma possui menos de 25 anos de idade. De outro, sem a perspectiva de mobilidade social ascendente, cresce, sobretudo entre os jovens, tanto a violência como a emigração da população com maior grau de escolaridade. 
Assim, em pleno limiar da sociedade do conhecimento, o Brasil precisa abandonar a concepção conservadora e ultrapassada do trabalho como obrigação pela sobrevivência para reconstituir uma nova transição do sistema escolar para o mundo do trabalho. $\mathrm{O}$ alongamento da expectativa média de vida está a exigir um novo papel à educação, a estar presente de forma continuada ao longo do ciclo de vida.

É dentro desse contexto de transição que a recente experiência do Município de São Paulo de inclusão social necessita ser compreendida. A estratégia paulistana de inclusão social oferece uma contribuição interessante em se tratando de um novo padrão de política pública que combina educação e trabalho associados à perspectiva de emancipação política, social e econômica da população excluída.

\section{Recebido em abril de 2004 e aprovado em junho de 2004.}

\section{Notas}

1. Para uma breve constatação acerca da evolução dos indicadores educacionais ver Campos et al., 2003.

2. Considera-se sobretrabalho as situaçóes relativas aos ocupados com jornada de trabalho acima de 44 horas semanais, aos aposentados e pensionistas que se mantêm ativos no mercado de trabalho, aos trabalhadores com mais de uma ocupação e ao trabalho de pessoas abaixo de 16 anos de idade.

3. Sobre os dados brasileiros como desemprego e homicídios, entre outros, comparativos com 175 países, ver Campos et al., 2004.

4. Para uma análise a respeito da crise da juventude no mercado de trabalho, ver Pochmann, 2000; Frigotto, 2004.

5. Mais detalhes em SDTs, 2003.

6. Sobre isso ver Amorim \& Pochmann, 2003.

7. Para uma constatação breve ver Henriques, 2000.

8. Para melhor análise ver Vannuchi \& Novaes, 2004.

9. As razóes para o destaque acerca da experiência de políticas públicas praticadas pela Secretaria do Desenvolvimento, Trabalho e Solidariedade podem ser encontradas em Pinsky, 2004; Oliveira, 2004; Campos, 2004.

10. Para mais detalhes ver Pochmann, 2003 e 2002.

11. Acesso à Bolsa Empreendedor mediante aprovação no processo seletivo semestral de projetos de pesquisa, conduzido a partir do Fórum Setorial das Instituições de Ensino Superior, instalado no Município de São Paulo.

Educ. Soc., Campinas, vol. 25, n. 87, p. 383-399, maio/ago. 2004

Disponível em <http://www.cedes.unicamp.br> 
Educação e trabalho: como desenvolver uma relação virtuosa?

12. Entre 2001 e 2003, no conjunto dos distritos administrativos atingidos pela estratégia de inclusão social, a taxa de homicídios por 100 mil habitantes caiu 21,8\%, ao passo que nos demais distritos a redução foi de 10,8\%; ver SDTS, 2004.

13. No período de 2001 a 2003 , a taxa de evasão caiu quase $50 \%$ nos distritos administrativos atendidos pelos programas sociais da PMSP; ver SDTS, 2004.

14. Para uma discussão mais detalhada e profunda a respeito da concepção de direitos entre a população atingida pelos programas sociais no município de São Paulo, ver Campos, 2004 .

\section{Referências bibliográficas}

AMORIM, R.; POCHMANN, M. (Org.). Atlas da exclusão social no Brasil. São Paulo: Cortez, 2003. v.1.

CAMPOS, A. Pobreza e direitos na cidade de São Paulo: a experiência da Secretaria do Desenvolvimento, Trabalho e Solidariedade. São Paulo: FFLCH/USP, 2004.

CAMPOS, A. et al. Atlas da exclusão social no Brasil. São Paulo: Cortez, 2003. v.2

CAMPOS, A. et al. Atlas da exclusão no mundo. São Paulo: Cortez, 2004. v.4

FRIGOTTO, G. Juventude, trabalho e educação no Brasil. In: Vannuchi, P.; Novaes, R. (Org.). Juventude e sociedade. São Paulo: Fundação Perseu Abramo, 2004.

HENRIQUES, R. Desigualdade e pobreza no Brasil. Rio de Janeiro: IPEA, 2000.

OlIVEIRA, C.A.B. (Coord.). Politicas de combate à pobreza no Município de São Paulo. São Paulo: Publisher, 2004.

PINSKY, J. Práticas de cidadania. São Paulo: Contexto, 2004.

POCHMANN, M. A batalha pelo primeiro emprego. São Paulo: Publisher, 2000 .

POCHMANN, M. Outra cidade é possivel. São Paulo: Cortez, 2002.

POCHMANN, M. Desenvolvimento, trabalho e solidariedade. São Paulo: Cortez, 2003. 
SÃO PAULO. Prefeitura. Secretaria do Desenvolvimento, Trabalho e Solidariedade. O jovem no mercado de trabalho brasileiro. São Paulo: PMSP/SDTS, 2003.

SÃO PAULO. Prefeitura. Secretaria do Desenvolvimento, Trabalho e Solidariedade. Pobreza e programas sociais: resultados da estratégia paulistana de inclusão social. São Paulo: PMSP/SDTS, 2004.

VANNUCHI, P.; NOVAES, R. (Org.). Juventude e sociedade. São Paulo: Fundação Perseu Abramo, 2004. 